\title{
Biopsychosocial model of addictions and other approaches
}

\begin{abstract}
Preparing the $5^{\text {th }}$ Edition of Diagnostic Manual of Mental Disorders provokes the experts to express their opinions concerning the new classification of the psychiatric disorders. It takes into account also addictions. For some time the discussion concerning behavioral forms of addictions and their position in new revisions of both international classifications of mental disorders has taken place. The American Society of Addiction Medicine expressed the opinion concerning the new definition of addictions stressing relevance of biological mechanisms - mainly the brain reward, motivation, memory and related circuitry, and also genetic and envoirmental factors. The new definition of addictions is congruent with biopsychosocial model of addictions, which has revolutionized the DSM III. In this article the history and basic assumptions of biopsychosocial approach, and other theories that were precursors to this model are recalled.
\end{abstract}

Keywords: biopsychosocial model, addictions, classifications of mental disorders.

DOI: $10.12923 / \mathrm{j} .0044-2011 / 123-4 / \mathrm{a} .12$

\section{INTRODUCTION}

Addictions are defined by the American Society of Addiction Medicine (ASAM) as: "a primary, chronic disease of brain reward, motivation, memory and related circuitry. Addiction affects neurotransmission and interactions within reward structures of the brain, including the nucleus accumbens, anterior cingulate cortex, basal forebrain and amygdala, such that motivational hierarchies are altered and addictive behaviors, which may or may not include alcohol and other drug use, supplant healthy, self-care related behaviors. Addiction also affects neurotransmission and interactions between cortical and hippocampal circuits and brain reward structures, such that the memory of previous exposures to rewards (such as food, sex, alcohol and other drugs) leads to a biological and behavioral response to external cues, in turn triggering craving and/or engagement in addictive behaviors" [1]. ASAM lists the following as important factors: "Genetic factors account for about half of the likelihood that an individual will develop addiction" [1]. Also environmental factors, resiliencies, which the individual acquires and culture that plays the role in how addiction becomes actualized in persons with biological vulnerability. ASAM lists also other factors such as the presence of biological deficit in the function of reward circuits, repeated engagement in addictive behaviors causing neuroadaptation, cognitive and affective distortions, disruption of healthy social supports, exposure to trauma, distortion in values, distortions in the persons' connections with self with others and with the transcendent, and the presence of co-occurring psychiatric disorders.
DSM IV introduced definition of substance-related disorders and the criteria for substance dependence as follows: tolerance, withdrawal, the substance is taken for a longer period that it was intended, persistent desire to cut down or control substance use, a great deal of time is spend to obtain the substance, important activities are given up or reduced because of substance use, the substance use is continued despite knowledge of having physical or psychological problems [2]. The mentioned ASAM definition of addiction, introduced officially for the first time the behavioral forms of addiction that is not included yet in DSM IV-TR. That implies the change to some extent in the interpretation of the model of addiction. However, in this respect the biopsychosocial model of addiction that was proposed over the past 20 years is still valid.

George Engel, a professor of psychiatry and medicine [3], introduced the psychosocial model of health and illness in 1977. Engel by writing his article in Science introduced a new way of thinking about human health problems - when we become ill it is not only that we are machines which are broken and another machine - doctor is repairing the former machine - patient. He was critical toward mechanistic idea of curing, he believed that "boundaries between the health and disease are far from clear... for they are diffused by cultural social and psychological considerations" [3]. Moreover, since that time the biopsychosocial model has become more and more popular in medical societies and medical schools. However, the biomedical model has not disappeared and is active as an alternative model and school of thought. In psychiatry, the biopsychosocial model influenced the conception of DSM III and particularly was the reason of creating of 
multiaxial system of the manual, and became more and more influential in psychiatric way of thinking. Another important step in introducing biopsychosocial model to psychiatry was cognitive behavioral forms of psychotherapy. It was implied to eating disorders, substance abuse, antisocial behavior and others. The development of the social and community psychiatry has the background in the biopsychosocial model.

Biological element reflects the physiological, neurochemical, and genetic factors that influence people's problems and need for medical help. We also should take in mind biological, somatic problems of the patients no matter what sort of leading problems they are centered on.

Psychological element of the model takes into account developmental psychological and the psychopathological problems. The counseling in those areas can be realized by the multimodel therapy, which is also based on biopsychosocial approach.

The social element of the model represents the theory of family systems, diversity - multicultural problems and the social justice problems.

Those mentioned above biopsychosocial elements are a background to the professional counseling organization in America. The professional counselors are trained in all those areas for effective interventions in society [3].

Karol L. Kumpfer, Ph.D., Eric P. Trunnell, Ph.D., and Henry O. Whiteside, Ph.D give another view of the historical background [4]. They believe, after Schwartz (1982) that "a major paradigm shift is moving the health sciences away from single-cause, linear models to multi-cause, interactive models" [4]. They also quote Kuhn's four paradigms of explanation of nature:

"1. formistic or categorical "black- white" thinking,

2. mechanistic or single-cause, single-effect, or chains of single causes thinking,

3. organicistic or multi-causal, integrative and holistic thinking and

4. contextual or relational or transactional thinking" [4].

The authors quote also the statement of Dewey and Bentley that "Behavior is viewed as an integral part of the persons and their environment. The unit of analysis is not just the person but an integration of elements in the environment and the person, resulting in his or her behavior" [4]. They also stress that the biomedical model, particularly in mechanistic conditioning approach did not work in the treatment of addictions. Other elements in the background of biopsychosocial approach according to the authors were humanistic psychology and the general system theory. The authors propose biopsychosocial vulnerability model "helpful in organizing etiological factors for substance abuse" [4]. Concerning biological factors, the authors list the following: genetic inheritance of different alcoholism syndromes, differences in metabolism and reactions to alcohol and other drugs, "in utero damage to the fetus temperament or other physiological differences that could occur at any time after birth" [4]. "When a number of these biological factors converge and interact with non-supportive and negative environmental conditions, however, these "diseases of life-style" can emerge" [4]. Concerning psychosocial factors, the authors list the following: family variables, community $\backslash$ school variables, peerlsocial variables. Authors [4] quote the term of reciprocal determinism (after Bandura 1989) that reflects "free choice in which people choose or shape environments to impact themselves in certain expected ways. To support a drug habit, a high-risk child may drop out of school and get a job, working with other young drug users. Whereas a low-risk child may choose to save money to assure that he or she can attend private religious colleges where alcohol and drug use are very low" [4]. The prevention and treatment in biopsychosocial model should be based on assessing the level of risk and protective factors in children and youth in order to target prevention services including family school and peer groups.

Interesting approach to biopsychosocial theory is that its history and background are covered in strategic priorities of BC Ministry of Health and Ministry responsible for Seniors [5]. It takes into account the traditional theories and the spiritual dimension that "has generally been underemphasized in most discussions of the biopsychosocial theory" [5]. The authors of the priorities use the term biopsychosocial as the biopsychosocial spiritual or holistic health concept. They list the traditional theories of addiction as follows: spiritual theory, disease theory, symptomatic theory, social theory, chemical dependency theory, learning theory. Since the majority of the listed theories are well known, I would like to quote some more information about spiritual and learning theories. "With regard to the spiritual theory, recovery is only possible if affected individuals acknowledge their inability to self- correct without the assistance of a spiritual force guiding them through the process of recovery" [5]. "The learning theory states that substance misuse is learned through the complex processes of behavioural acquisition and reinforcement...it implies that treatment should focus on creating behavioural change usually through the structured system of behavior modification". The authors have generated several hypothesis from the biopsychosocial theory. Some of them are a bit controversial: for instance "substance misuse embraces a variety of syndromes including dependency syndrome and substance misuse related disabilities... because the elements in the experience of addiction will differ between individuals, there is no one superior treatment for all substance misuse, recovery may or may not require abstinence, depending upon the degree of severity and/or the type of syndrome" [5].

Particularly the problem of abstinence is a matter of different opinions and points of view. In my opinion, however it is a necessary element of recovery process.

Now I would like to quote some other schools of thoughts that could be recognized as precursors of the biopsychosocial approach. M. Masiak [6] states that "however biopsychosocial approach in medicine takes into account all determinants of health and illness". Other approaches and models highlighted the psychological and social dimensions in terms of personality and social group structures and functioning. It is the community psychiatry concept (Tuke, Connolly and others), which is developing in various types of therapeutic communities and the evolutionary approach (Hulings Jackson, Jan Mazurkiewicz), that assume both: a stage-by-stage evolution of human psychic life (which could be stated also in term of social life) 
as a psychological norm, and a psychopathology as a reverse process, called dissolution as a process of devolving to an earlier stage of evolution of human psychic life. This process is, according to Mazurkiewicz, caused by what was later described as a hypofrontality. These dissolutions have different forms and depth and differ in terms of reversibility and irreversibility. According to this approach, all types of addictions can be interpreted as dissolution, which can be reversible in most cases. Other authors (Lende, Smith) [7] assume that the evolutionary theory can inform the biopsychosocial approach to addictive behavior through the use of adaptionist thinking. On the one hand the authors examine three components of drug use and abuse: "biological mechanism (mesolimbic dopamine) a developmental trajectory (attachment) and a social phylogeny (dominance submission, social dependence). On the other hand, they examine how inequality affects drug abuse and how social dependence and manipulative behaviors can play a role in relationships with drugs" [7]. The authors try to find the way of the adaptive approach to be applied to interventions against addictive behavior. They believe that "the significant heritability seen in drug abuse can relate to diverse processes in different areas from tolerance to specific drugs and individual sensitivity in the dopamine system to the effect of attachment of life history strategies and the role of evolutionary dependence in certain types of addictive behavior" [7]. The evolutionary approach according to the authors gives the possibility for identification and prevention of early onset substance abuse. The ways to arrange it are environmental interventions that improve general conditions for the developing child and therefore the deviant strategies of substance abusers are diminished.

The psychosocial elements of biopsychosocial approach can be more transparent if seen based to another school of thought, which was another precursor of the biopsychosocial approach, namely the transactional analysis (TA). TA was originated by Eric Berne, became a world school of psychotherapy and influenced many other areas as management, education, and the social group analysis. One of the authors who applied TA to the analysis of social group structures and functioning was mentioned above M. Masiak [6]. I would like to present the basic TA philosophy formulated by CM Steiner 1974 - "human being are by nature inclined to and capable of living in harmony with themselves, each other and nature. If people are unhealthy, uninterested in learning, uncooperative, selfish, or disrespectful of life, it is the result of external oppressive influences, which overpower the more basic positive life tendency that is built-in to them. Even when overpowered this tendency remains dormant, so that it is always ready to express itself when oppression lifts. Even if it is not given a chance to be expressed in a person's lifetime, this human life tendency is passed on to each succeeding generation of newborns" [6]. I would like to point two aspects of TA, because they among others can make possible to analyze in new perspective individual functioning of human and the functioning of social groups. The first is script of life (after M. Masiak [6]). The script or scenario is written in our early childhood and we perform it all our life, unless we decide one day to change it and to change our life. Registered in the script are injunctions and counter-injunctions of our parents, survival conclusions of our "little professor" and other elements that strictly determine our life performance." The script of life is a very important variable that influences our life decisions and behavior, besides other factors as heritability, social environment and others. There are some negative types of script of life, which can play important role in the process of addiction. Another point is the game (after M. Masiak) "It is a recurring series of transactions often repetitive, superficially rational, with the concealed motivation and outcome that could be dramatic or at least make impossible any real development or real positive changes in the situation. In this pattern of transactions, many forms of manipulating the other person or persons are used. The basic game, often played in childhood is: mine is better than yours is. The roles that people play in games usually form "the drama triangle" (after CB Karpman) and comprise: Victim, Rescuer and Persecutor" [6]. Games are a form of aggression and manipulation, tend to be continued for long time and influence functioning of many families and other social groups, and should be taken into account in analyzing and assessing the structure and functioning of the society. The social groups that members are involved in games cannot play role of protective and supportive background for its members. Also in terms of addiction all those aspects should be taken into account in biopsychosocial perspective and type of thinking.

\section{REFERENCES:}

1. Definition of addiction. American Society of Addiction Medicine. The Voice of Addiction Medicine. [http://www.asam.org/researchtreatment/definition-of-addiction]

2. Diagnostic and statistical manual of mental disorders ( $4^{\text {th }}$ ed., text rev). Washington: American Psychiatric Association; 2000.

3. Kaplan DM, Coogan SL. The next advancement in counseling: the bio-psycho-social model VISTAS Online. American Counseling Association; 2005. p. 17-25. [http://counselingoutfitters.com/vistas/vistas05/ Vistas05.art03.pdf]

4. Kurnpfer KL, Trunnell EP, Whiteside HO. The biopsychosocial model: application to the addictions field. In: RC. Engs (ed). Controversies in the addiction's field. Dubuque: Kendal-Hunt; 1990. p. 55-67. [http:// www.indiana.edu/ engs/cbook/tabcont.html]

5. The biopsychological theory: a comprehensive descriptive perspective on addiction. Alcohol and drug services. Adult Addictions Services Branch. Alcohol and Drug Services British Columbia Ministry for Children and Families, 1996. [http://citeseerx.ist.psu.edu/viewdoc/downloa $\mathrm{d}$;jsessionid=4ECC3F44D969868215F5BDC376122864?doi=10.1.1.89 $.1099 \&$ rep $=$ rep $1 \&$ type $=$ pdf]

6. Masiak M. Personality and social group structure, function and gender in terms of transactional analysis. In: C. Wheatley, RP. Badillo, RB Calabretta, R. Magliola. Humanization of Social Life. Vol. 1. Theory and Challenges. Washington: Council for Research in Values and Philosophy; 2004. p. 287-98. [http://books.google.pl/books?id=g1Ehj_Kv VoYC\&pg=PA287\&lpg=PA287\&dq=Personality, + Social+Groups + Structure, + Functioning + and + Transfer+in+Terms + of + Transactio nal+Analysis \& source $=$ b1\&ots $=$ J9LomFrPvm\&sig $=$ jMlkgukJ4uA QCAhdFxjJn3OKJrY\&hl=pl\&sa=X\&ei=-aD6T7DNG8qi0QX7myhBw\&ved $=0$ CFsQ6AEwAg\#v=onepage $\& \mathrm{q}=$ Personality $\% 2 \mathrm{C} \% 20$ Social $\% 20$ Groups $\% 20$ Structure $\% 2$ C $\% 20$ Functioning $\% 20$ and $\% 20$ Transfer\%20in \%20Terms\%20of\%20Transactional\%20Analysis\&f=false]

7. Lende DH, Smith EO. Evolution meets biopsychosociality: an analysis of addictive behavior. Addiction. 2002;97(4):447-58. 


\section{Informacje o Autorce}

Dr n. med. Jolanta MaSIAK - adiunkt, Katedra i Klinika Psychiatrii, Uniwersytet Medyczny w Lublinie.

\section{Corresponding Author}

Jolanta Masiak

Katedra i Klinika Psychiatrii,

Uniwersytet Medyczny w Lublinie

ul. Głuska 1, 20-439 Lublin

tel. 509-367-574

E-mail: jolantamasiak@wp.pl 